\title{
Characterization of the Mercapturic Acid Pathway, an Important Phase II Biotransformation Route, in a Zebrafish Embryo Cell Line
}

\author{
Alena Tierbach, Ksenia J. Groh, René Schoenenberger, Kristin Schirmer,* and Marc J.-F. Suter* \\ Cite This: Chem. Res. Toxicol. 2020, 33, 2863-2871 \\ Read Online
}

ABSTRACT: In view of the steadily increasing number of chemical compounds used in various products and applications, high-throughput toxicity screening techniques can help meeting the needs of 21 st century risk assessment. Zebrafish (Danio rerio), especially its early life stages, are increasingly used in such screening efforts. In contrast, cell lines derived from this model organism have received less attention so far. A conceivable reason is the limited knowledge about their overall capacity to biotransform chemicals and the spectrum of expressed biotransformation pathways. One important biotransformation route is the mercapturic acid pathway, which protects organisms from harmful electrophilic compounds. The fully functional pathway involves a succession of several enzymatic reactions. To investigate the mercapturic acid pathway performance in the zebrafish embryonic cell line, PAC2, we analyzed the biotransformation products of the reactions comprising this pathway in the cells exposed to a nontoxic concentration of the reference substrate, 1-chloro-2,4dinitrobenzene (CDNB). Additionally, we used targeted proteomics to measure the expression of cytosolic glutathione S-transferases (GSTs), the enzyme family catalyzing the first reaction in this pathway. Our results reveal that the PAC2 cell line expresses a fully functional mercapturic acid pathway. All but one of the intermediate CDNB biotransformation products were identified. The presence of the active mercapturic acid pathway in this cell line was further supported by the expression of a large palette of GST enzyme classes. Although the enzymes of the class alpha, one of the dominant GST classes in the zebrafish embryo, were not detected, this did not seem to affect the capacity of the PAC2 cells to biotransform CDNB. Our data provide an important contribution toward using zebrafish cell lines, specifically PAC2, for animal-free highthroughput screening in toxicology and chemical hazard assessment.

\section{INTRODUCTION}

State-of-the-art approaches in drug discovery and chemical hazard assessment rely on high-throughput technologies that enable affordable screening of large numbers of chemicals. Cell-based systems, especially continuous cell lines, are particularly suitable for such purposes. They are easy to handle, provide an unlimited supply of homogeneous cells and are not subject to the ethical concerns surrounding the use of living organisms. Yet, to fully exploit the potential of cell lines in chemical toxicity testing, it is necessary to understand their repertoire of active biotransformation pathways.

A major biotransformation route for electrophilic substances is the mercapturic acid pathway for which the glutathione $S$ transferase (GST) enzyme family plays an important role ${ }^{1-3}$ (Figure 1). GSTs catalyze the first reaction of the mercapturic acid pathway, i.e. the conjugation of the nucleophile glutathione with the electrophilic group of the foreign or endogenous target compound. ${ }^{4,5}$ This initial conjugation reaction occurs within the cells. Subsequently, members of the ATP-binding cassette/multidrug resistance-associated protein transporter family ( $\mathrm{ABCC} / \mathrm{MRP}$ ) bring the glutathione conjugate to the cell surface. ${ }^{6,7}$ On the cell surface, the conjugate is further biotransformed by membrane-bound $\gamma$ - glutamyl transferases and dipeptidases, which act to successively remove the $\gamma$-glutamyl and glycyl group from the glutathione conjugate. ${ }^{2,8}$ The cysteine conjugate produced in this way re-enters the cell via transporters and is then acetylated to the $N$-acetyl-L-cysteine $\mathrm{S}$-conjugate by $\mathrm{N}$-acetyl transferases. ${ }^{2,9-11}$ The $N$-acetyl-L-cysteine S-conjugate, which is the mercapturic acid form of the parent chemical compound, is the final product of the pathway and usually excreted by the cells and eliminated from the body. ${ }^{2,12}$

Although the biotransformation of chemicals within the mercapturic acid pathway is generally considered a detoxification mechanism, some chemical groups, including isocyanates and haloalkenes, can also be bioactivated via this pathway to toxic transformation products. ${ }^{1,12-14}$ Therefore, an accurate interpretation of toxicity data would require knowl-

Received: July 31,2020

Published: September 29, 2020 


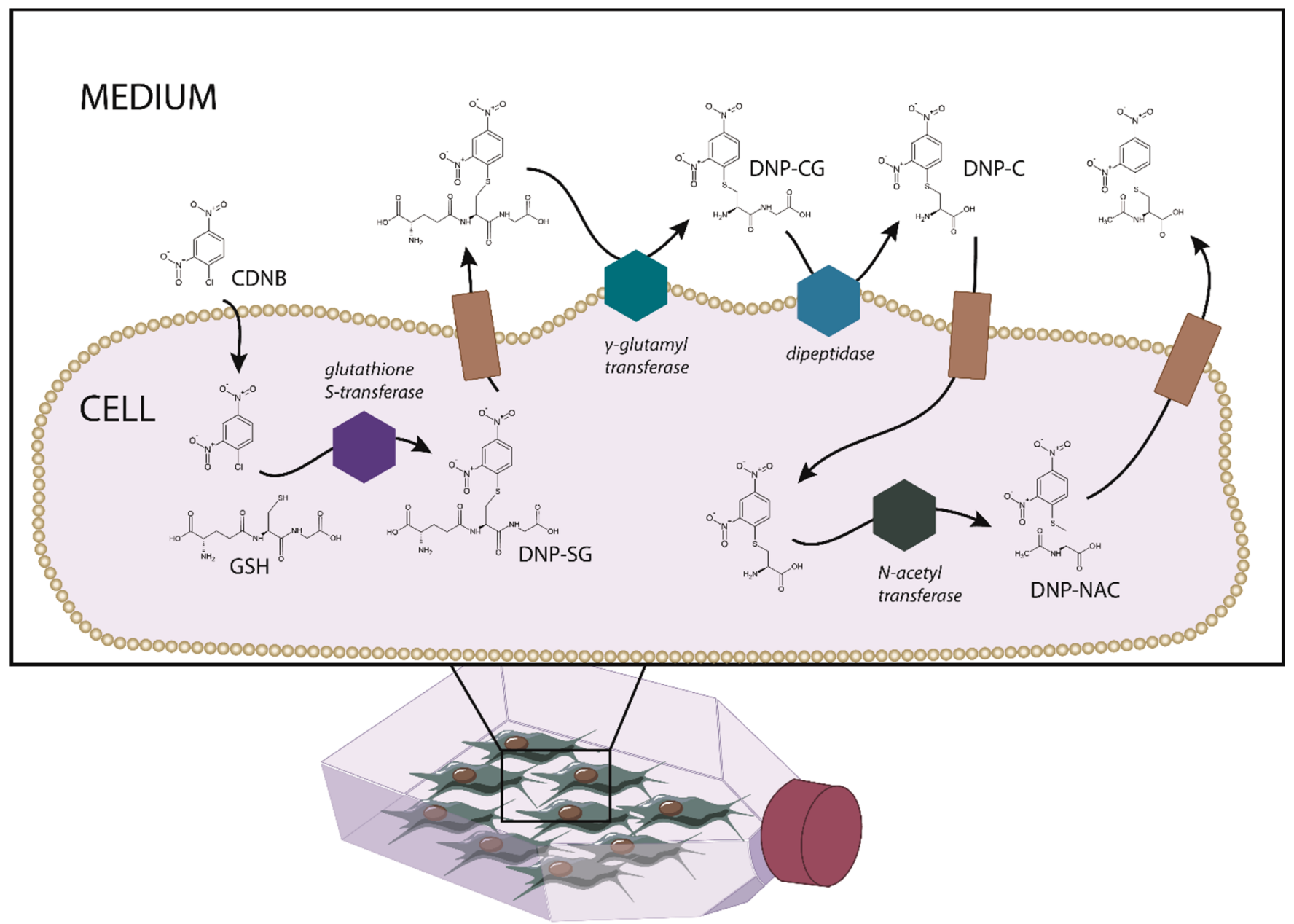

Figure 1. Biotransformation of 1-chloro-2,4-dinitrobenzene (CDNB) through the mercapturic acid pathway. CDNB enters the cell and is conjugated with glutathione (GSH) to 2,4-dinitrophenyl-S-glutathione (DNP-SG), which is further biotransformed to 2,4-dinitrophenyl cysteinylglycine (DNP-CG), 2,4-dinitrophenyl cysteine (DNP-C), and 2,4-dinitrophenyl $N$-acetylcysteine (DNP-NAC), the mercapturate. See the Introduction for further details on this pathway.

edge about the functionality of the mercapturic acid pathway in cell-based systems.

Despite zebrafish (Danio rerio) being very popular in life sciences and toxicology, and one of the best-researched vertebrates with well-described morphology, genetics and molecular pathways, cell lines derived from this model organism have received relatively little attention in toxicological studies thus far, ${ }^{15}$ but could provide a useful test system as well. For example, the zebrafish embryonic fibroblast cell line, PAC2, has been successfully used for cytotoxicity assessment of antibiotics, flame retardants, and genotoxicants. $^{16-19}$

Considering the relevance of cell cultures as a replacement for in vivo vertebrate models in toxicity testing, we aimed to gain knowledge about the biotransformation capacity of the zebrafish PAC2 cell line in order to broaden its application field. To characterize the mercapturic acid pathway in this test system, we exposed the PAC2 cells to a model GST substrate, 1-chloro-2,4-dinitrobenzene (CDNB) and (i) measured the abundance of cytosolic GSTs, the enzyme family that catalyzes the first reaction in this pathway, by targeted proteomics, and (ii) analyzed the expected biotransformation products using liquid chromatography high-resolution mass spectrometry (LC-HRMS).

\section{EXPERIMENTAL PROCEDURES}

Chemicals and Reagents. Nanopure water was obtained from Barnstead Nanopure, Fisher Scientific (United States). Methanol and ethanol for HPLC (both gradient grade, $\geq 99.8 \%$ ), formic acid, Versene solution, Alamar Blue and CFDA-AM were from Fisher Scientific (United States). Dimethyl sulfoxide (DMSO), 1-chloro-2,4dinitrobenzene (CDNB, CAS: 97-00-7, purity: $\geq 99 \%$ ), 5-chloro-2,4dinitrotoluene (CDNT, CAS: 51676-74-5, purity: 97\%), the Glutathione S-Transferase (GST) Assay Kit (CS0410), and Neutral Red were from Sigma-Aldrich (United States). Leibovitz L-15 medium was obtained from Invitrogen (United States) and fetal bovine serum (FBS) from PAA Laboratories (Switzerland). Trypsin was purchased from Biowest (France).

Routine PAC2 Cell Culture. The PAC2 fibroblast cell line was kindly provided to the Schirmer group by Dr. Nick Foulkes (MaxPlanck-Institute for Developmental Biology, Tübingen, Germany). This adherence-dependent cell line was originally derived from $24 \mathrm{~h}$ post fertilization (hpf) zebrafish embryos via spontaneous immortalization; ${ }^{20}$ we selected it under the premise that, based on its origin, it is a suitable representative of zebrafish embryo tissue explored in our prior work. ${ }^{21}$ The cells were routinely cultured in Leibovitz L-15 medium supplemented with $10 \% \mathrm{FBS}$ at $26 \pm 2{ }^{\circ} \mathrm{C}$ in ambient atmosphere in an incubator in the dark. The cells were subcultured every 5-10 days at a ratio of $1: 2$ to $1: 3$ after the formation of a confluent monolayer. For subcultivation, cells were washed twice with Versene and detached from the flask surface with trypsin. 
CDNB Toxicity. The analysis of CDNB biotransformation products requires the selection of a suitable CDNB exposure concentration, i.e., one that is not yet cytotoxic but sufficiently high to allow analytical detection of the products of interest. To define the nontoxic concentration ( $\mathrm{NtC}$ ) of $\mathrm{CDNB}$ in our test system, we performed a modified version of the RTgill-W1 cell line assay. ${ }^{22-24}$

For the exposure medium, a fresh stock solution at a concentration of $3.2 \mathrm{mg} / \mathrm{mL}(15.8 \mathrm{mM})$ of CDNB dissolved in DMSO was prepared on the day of exposure. This stock solution was then used to establish a dilution series of CDNB in DMSO at the day of use, such that a 200 -fold dilution in the final exposure medium yielded nominal concentrations of $1600,1280,1024,819.2,655.36$, and $419.43 \mathrm{ng} /$ $\mathrm{mL}$, corresponding to $7.90,6.32,5.06,4.04,3.24$, and $2.07 \mu \mathrm{M}$, with a final DMSO content of $0.5 \%(\mathrm{v} / \mathrm{v})$. These solutions were well mixed by inverting and $10 \mathrm{~min}$ shaking on a horizontal shaker. A $1 \mathrm{~mL}$ aliquot of each final exposure solution was sampled from the vial and stored at $-20{ }^{\circ} \mathrm{C}$ until chemical quantification to verify the initial exposure concentrations.

For exposure experiments, PAC2 cells were seeded in routine cell culture medium (L-15 with $10 \%$ FBS at a cell seeding density of 30 000 cells $/ \mathrm{ml}$ into 24-well plates (approximately 316000 cells $/ \mathrm{cm}^{2}$ ). After $24 \mathrm{~h}$, the attached cells were washed with $2 \mathrm{~mL}$ of L-15 medium supplemented with $5 \%$ FBS. The washing medium was then removed, and $2 \mathrm{~mL}$ exposure medium (L-15 with 5\% FBS and DMSO 0.5\% (v/ v)) with the different CDNB concentrations was added to triplicate wells per concentration. The cells were exposed in paraffin-sealed plates for $24 \mathrm{~h}$ in the dark at $26^{\circ} \mathrm{C}$ as explained above.

Upon termination of exposure, samples were taken for chemical analysis of CDNB and viability tests with three fluorescent dyes were performed on the same set of cells using a fluorescent multiwell plate reader (Tecan Infinite 2000, Switzerland). Specifically, Alamar Blue was used to measure metabolic activity, 5-carboxyfluorescein diacetate acetoxy-methyl ester (CFDA-AM) to assess cell membrane integrity, and Neutral Red to measure lysosomal membrane integrity. ${ }^{22,23,25}$ Cell viability assessment was performed in three independent biological replicates with cells originating from different passage numbers (passage 69 to 71 ).

To verify CDNB exposure concentrations, CDNB in the exposure medium was analyzed using a quadrupole-orbitrap mass spectrometer (QExactive Plus, Thermo Scientific, United States) and atmospheric pressure chemical ionization in negative ion mode (APCI $(-))$, based on the method developed by Tierbach et al., ${ }^{26}$ using dissociative and nondissociative electron capture ions originating from the CDNB precursor under APCI. Without enrichment, the limit of quantitation was $\geq 17 \mathrm{ng} / \mathrm{mL}(83.9 \mathrm{nM})$.

Exposure Experiments for the Analysis of GST Expression and CDNB Biotransformation. To analyze the mercapturic acid pathway in the PAC2 embryonic cell line, we characterized the constitutive expression of GST proteins, investigated their regulation by $\mathrm{CDNB}$ exposure at the $\mathrm{NtC}$, and examined the formation of CDNB biotransformation products. Both exposure experiments, for the protein expression analysis and for measuring biotransformation products, were run in parallel in four independent biological replicates, each in one $75 \mathrm{~cm}^{2}$ cell culture flask, with cell passage numbers 71 to 74 . According to the results of the cell viability assays and based on the determined $\mathrm{NtC}$ (see also the Data Evaluation below), a CDNB stock solution with a concentration of $7.4 \mathrm{mg} / \mathrm{mL}$ ( $36.5 \mathrm{mM})$ was prepared freshly in DMSO on the day of exposure. Subsequently, the exposure medium was prepared by diluting the CDNB stock solution in DMSO such that a 200 -fold dilution in the final exposure medium would yield a nominal concentration of 368 $\mathrm{ng} / \mathrm{mL}(1.8 \mu \mathrm{M})$ with a final DMSO content of $0.5 \%(\mathrm{v} / \mathrm{v})$.

Prior to exposure, cells were seeded in L-15 medium supplemented with $10 \% \mathrm{FBS}$ at a cell seeding density of 450000 cells $/ \mathrm{ml}$ into T-75 (approximately $60000 \mathrm{cells} / \mathrm{cm}^{2}$ ) cell culture flasks. After $24 \mathrm{~h}$, the attached cells were washed with $10 \mathrm{~mL}$ of the exposure medium, i.e., L-15 supplemented with 5\% FBS. Subsequently, the cells were exposed to the CDNB NtC for $24 \mathrm{~h}$ at $26^{\circ} \mathrm{C}$ in the dark. In parallel, control samples were prepared by cultivating cells in CDNB-free medium under the same conditions. Sampling of medium and cells was performed as follows: at the respective time point $(1,3,6$, and 24 $\mathrm{h})$, the exposure medium ( $10 \mathrm{~mL}$ from each of the two flasks: one for biotransformation and one for GST protein analysis) was removed from the cells, transferred to clean sampling glass vials and stored at $-20{ }^{\circ} \mathrm{C}$. The cells were washed once with L-15 medium supplemented with 5\% FBS, then twice with Versene, then detached from the flask surface through trypsinization, and centrifuged down for $3 \mathrm{~min}$ at $1000 \mathrm{rcf}$, RT. The pellet was resuspended in $1 \mathrm{~mL}$ of phosphate-buffered saline $(\mathrm{pH} 7)$, transferred to a clean $1.5 \mathrm{~mL}$ Eppendorf tube, and centrifuged for $5 \mathrm{~min}$ at $10000 \mathrm{rcf}, \mathrm{RT}$. After the supernatant was removed, the samples were snap-frozen in liquid nitrogen and stored at $-80{ }^{\circ} \mathrm{C}$. Unexposed cells were sampled at the $24 \mathrm{~h}$ time point as control for CDNB biotransformation and at the 1 , 3, 6, and $24 \mathrm{~h}$ time points as control for the GST protein levels.

Protein Expression Analysis. Protein extraction and trypsin digestion were performed as described in Tierbach et al. ${ }^{27}$ Briefly, the collected cells were homogenized in lysis buffer and the proteins precipitated using the methanol/chloroform method. Subsequently, proteins in each sample were digested with trypsin at $37^{\circ} \mathrm{C}$ for $16 \mathrm{~h}$. The samples were desalted using reversed-phase cartridges (Sep-Pak Vac tC18, Waters, United States) and stored at $4{ }^{\circ} \mathrm{C}$ until targeted proteomics analysis on the TSQ Vantage (Thermo Scientific, United States), carried out as described in Tierbach et al. ${ }^{27}$

Analysis of CDNB Biotransformation Products in PAC2 Cells and Exposure Medium. Prior to all sample preparations, cell and medium samples were spiked with $2.5 \mu \mathrm{L}$ of a reference standard, 2,4dinitrotoluene-S-glutathione (DNT-SG), as described in ref 21 . The extraction of CDNB biotransformation products from the cells was performed according to the method established in ref 21 , with some modifications. Briefly, the samples were thawed, taken up in $500 \mu \mathrm{L}$ methanol and homogenized. Subsequently, the sample lysate was centrifuged (6 min, $10000 \mathrm{rcf}, \mathrm{RT})$, the supernatant filtered, evaporated, and redissolved in $25 \mu \mathrm{L}$ of nanopure water with $0.1 \%$ formic acid.

Exposure medium was collected at each time point from cells exposed to CDNB for GST protein and CDNB biotransformation analysis, as described above. The exposure medium collected from parallel flasks at the same time point was pooled, resulting in a total volume of $20 \mathrm{~mL}$. To clean and enrich the CDNB biotransformation products, the samples were acidified through addition of $0.1 \%$ formic acid and $15 \mathrm{~mL}$ were loaded onto reversed-phase cartridges (Sep-Pak Vac tC18, Waters, United States). The samples were eluted with 800 $\mu \mathrm{L}$ of $80 \%$ aqueous acetonitrile solution with $0.1 \%$ formic acid, evaporated using a vacuum centrifuge at $30^{\circ} \mathrm{C}$, redissolved in $25 \mu \mathrm{L}$ of nanopure water with $0.1 \%$ formic acid, and stored at $4{ }^{\circ} \mathrm{C}$. The LCHRMS analysis of CDNB biotransformation products in cells and in medium samples was performed as described in detail in ref 21 . In some cases, we observed the generation of DNP-CG through gasphase reactions in the ESI source, clearly distinguishable from the biological transformation product DNP-CG by its longer retention time (further details are presented in the Supporting Information "Generation of DNP-CG through gas-phase reactions in the ESI source").

Data Evaluation. Data visualization, $t$ test (to analyze changes in protein expression upon exposure to CDNB), and one-way ANOVA (to analyze differences in $\mathrm{EC}_{50} / \mathrm{NtC}$ calculated based on different fluorescent dyes) were performed using GraphPad Prism version 7.05 for Windows (GraphPad Software, La Jolla, CA, www.graphpad.com). Values were considered significantly different if $p<0.01$.

In cell viability assays, the background fluorescence of CDNB in the absence of cells was subtracted from data obtained with the three fluorescent dyes (AlamarBlue, CFDA-AM and Neutral Red) and normalized to a CDNB-free solvent control. The $\mathrm{EC}_{50}$ and $\mathrm{NtC}$ were calculated based on the nominal and measured concentrations with the algorithm described by Stadnicka-Michalak et al. ${ }^{28}$

The analysis of mass spectrometric data of CDNB biotransformation products was performed with Thermo Xcalibur 3.0.63 (Thermo Fisher Scientific Inc.) as described in ref 21.

The analysis of targeted proteomics data for GST expression was performed with Skyline ${ }^{29}$ as described in Tierbach et al. ${ }^{27}$ 


\section{RESULTS}

Determination of $\mathrm{EC}_{50}$ and Nontoxic CDNB Concentrations. To define the toxic range and the nontoxic concentration $(\mathrm{NtC})$ of $\mathrm{CDNB}$, we assessed the cell viability of PAC2 cells by using fluorescent dyes that reflect the state of metabolic activity (AlamarBlue), cell membrane integrity (CFDA-AM), and lysosomal integrity (Neutral Red). Data were plotted in three ways (SI Figure 1): based on nominal concentrations, the measured CDNB starting concentrations, and the geometric mean of concentrations measured at the beginning and at the end of the exposure $\left(c_{0 h}\right.$ and $c_{24 h}$; SI Table 1). The discrepancy between nominal vs measured values at the start of exposure appears to be due to losses (about $42 \%$, SI Table 1) in exposure medium preparations while the difference between measured and geometric mean measured concentrations is due to losses during exposure (see also below). There were no significant differences between $\mathrm{EC}_{50} / \mathrm{NtC}$ values calculated based on different fluorescent dyes (Alamar Blue, CFDA-AM and Neutral Red; SI Figure 1). Therefore, average effective concentrations and NtCs were calculated (SI Table 2).

The concentration-response data were used to select the $\mathrm{NtC}$ for subsequent biotransformation studies; indeed, cells should be fully functional to allow biotransformation to ensue. We chose the lowest $\mathrm{NtC}$ (based on nominal: $368 \mathrm{ng} / \mathrm{mL}=$ $1.8 \mu \mathrm{M}$; SI Figure 1D, CFDA-AM) to proceed.

Kinetics of CDNB in the Culture System. CDNB concentrations were monitored with and without cells in order to differentiate abiotic and cell-related processes (Figure 2).

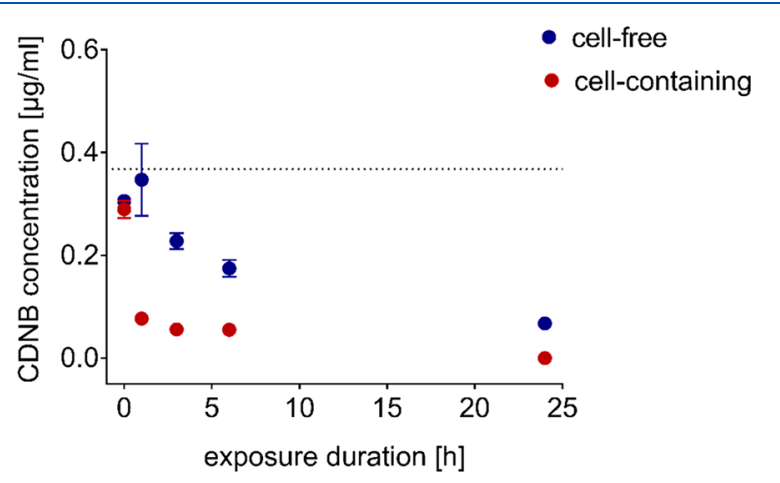

Figure 2. Measured 1-chloro-2,4-dinitrobenzene (CDNB) concentrations in the medium from cell-free (blue) and cell-containing (red) culture flasks. The nontoxic concentration $(\mathrm{NtC})$ based on the nominal concentrations $(368 \mathrm{ng} / \mathrm{mL})$ is indicated as a dotted line. The data is shown as mean of four replicates from cell-containing flasks and three replicates from cell-free flasks. Vertical lines indicate the standard error.

While substantial losses were encountered already in the absence of cells, losses occurred significantly faster and to a larger degree when cells were present, demonstrating cellbased biotransformation of CDNB.

Analysis of GST Protein Expression upon Exposure to CDNB. Targeted proteomics revealed the presence of cytosolic GST classes zeta (Gstz), theta (Gstt1a), mu (Gstm1,2 and Gstm 1,2,3), pi (Gstp1 and Gstp1,2), rho (Gstr), and omega (Gsto1 and Gsto2) in the PAC2 cells, while members of the class alpha were not detected (Figure 3 and SI Figure 2). Constitutive expression levels changed slightly but significantly for some of the GSTs over time (SI Figure 2) but no significant changes occurred in response to CDNB exposure at $\mathrm{NtC}$ (Figure 3). These data demonstrate the expression of a large pool of GSTs in the PAC2 cells, suggesting that the mercapturic acid pathway could be initiated by the presence of an appropriate substrate, which was studied next.

Identification of Biotransformation Products of the Mercapturic Acid Pathway. Considering both medium and cell-derived analyses together, all but one of the four biotransformation products of the mercapturic acid pathway were identified. Their identity was confirmed by the excellent fit of the mass determined, the characteristic isotope ratios and fragmentation pattern as described in ref 21 (Figure 4; SI Figures 3-5, and SI Table 3). In PAC2 cells, the highest concentration of the first biotransformation product in the mercapturic acid pathway, 2,4-dinitrophenyl-S-glutathione (DNP-SG), was detected at the earliest sampling point $(1 \mathrm{~h}$ of exposure). Subsequently, its concentration in the cells decreased continuously and reached a value below the limit of detection at $24 \mathrm{~h}$ of exposure (Figure 4A). No other biotransformation products of the mercapturic acid pathway could be detected in the PAC2 cells.

DNP-SG was also detected in the exposure medium already after $1 \mathrm{~h}$ of exposure, with concentrations increasing thereafter (Figure 4B). Additionally, two further CDNB biotransformation products, 2,4-dinitrophenyl cysteinylglycine (DNP-CG) and 2,4-dinitrophenyl $N$-acetylcysteine (DNP-NAC), were present in the exposure medium. These 2,4-dinitrophenol conjugates were detected after 1 (in case of DNP-CG), 3, 6, and $24 \mathrm{~h}$ of exposure in more than one replicate. Compared with DNP-SG, their signal intensity was rather low (Figure $4 C, D)$. One further intermediate biotransformation product of the mercapturic acid pathway, 2,4-dinitrophenyl cysteine (DNP-C), was neither detected in the cells nor in the exposure medium.

\section{DISCUSSION}

In model systems such as cell cultures, knowledge about active biotransformation pathways and their influence on the manifestation of toxicity is crucial for understanding and predicting toxicity. With the aim to start characterizing an important phase II biotransformation route, the mercapturic acid pathway, we studied the expression of cytosolic GSTs and analyzed biotransformation products of a model substrate, CDNB, in the zebrafish embryonic cell line, PAC2. Our data demonstrate that the cells express a wide range of GSTs and that the mercapturic acid pathway is fully active in this cell line.

PAC2 Cells Deplete CDNB as Compared to Cell-Free Controls. Reduction of CDNB levels occurred both in the presence and absence of cells but the loss was significantly faster and more pronounced in the presence of cells, thereby providing strong indication that $\mathrm{CDNB}$ is taken up and biotransformed by PAC2 cells. Several processes could be contributing to the substance loss in the absence of cells. First, there could be abiotic degradation of CDNB due to light exposure or hydrolysis, but this was unlikely to occur because the culture plates were incubated in the dark and because this compound lacks functional groups susceptible to abiotic hydrolysis. ${ }^{30}$ Second, sorption of CDNB to the polystyrene of cell culture flasks is possible but would explain only a small fraction of CDNB loss over time: a loss of only about $1 \%$ can be predicted by partitioning to plastic (SI Figure 6) based on a kinetic model by Fischer et al. ${ }^{31}$ The model takes into account the $\log K_{\text {ow }}\left(C D N B \log K_{\text {ow }}=2.89^{32}\right)$, the amount of FBS\% in 
Gstz

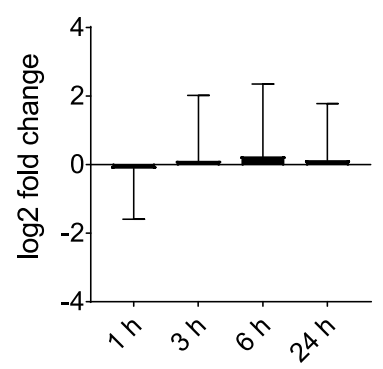

Gstm1,2,3

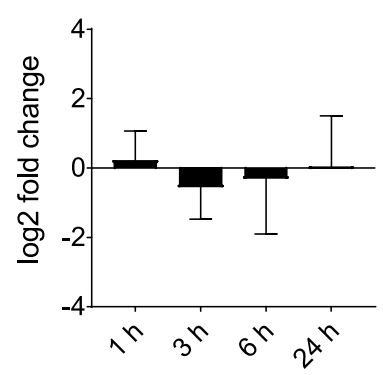

Gstr

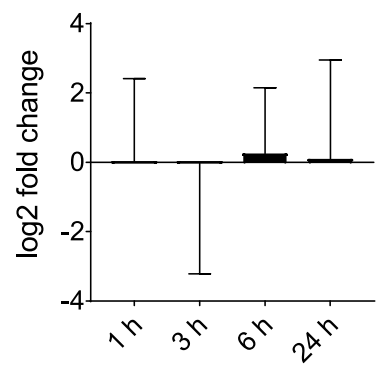

exposure duration
Gstt1a

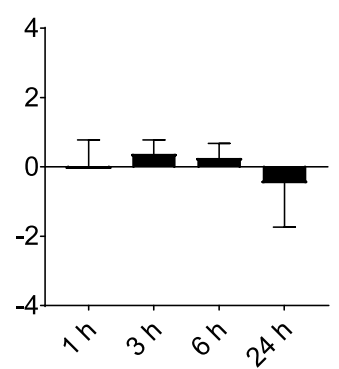

Gstp1

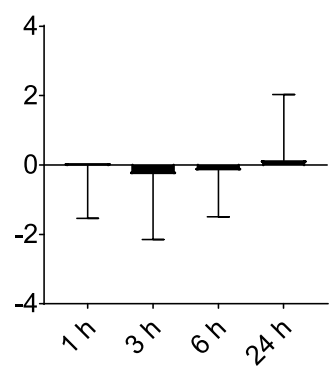

Gsto1

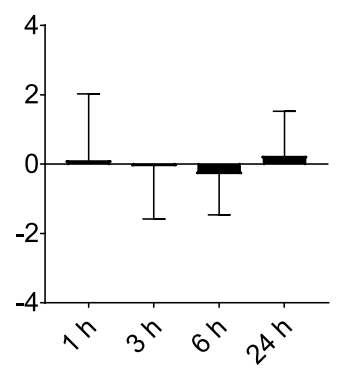

exposure duration
Gstm1,2

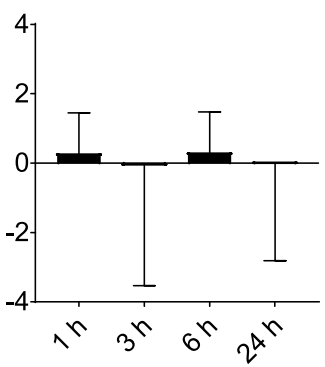

Gstp1,2

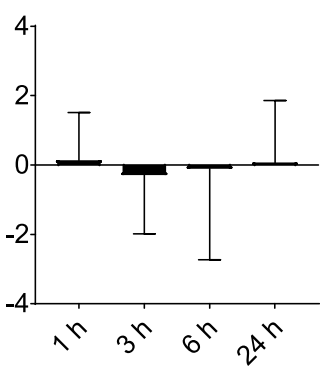

Gsto2

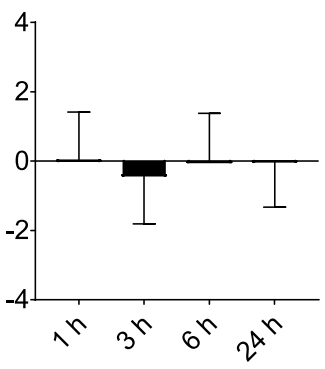

exposure duration

Figure 3. Expression of cytosolic glutathione S-transferases (GSTs) in the PAC2 cell line exposed to the nontoxic concentration of 1-chloro-2,4dinitrobenzene (CDNB) for 1, 3, 6, and $24 \mathrm{~h}$. Data is normalized to the housekeeping proteins $\beta$-actin and $40 \mathrm{~S}$ ribosomal protein $\mathrm{S} 18$ and shown as $\log 2$ fold change to the respective CDNB-free control taken at the same time point. The mean of four replicates (from four independent T75 cell culture flask) and standard error are shown. For expression analysis, the normalized peak areas of peptides belonging to the same enzyme or several isoenzymes from the same class were cumulated. No significant differences between exposure and control samples taken at the same time point were observed ( $p>0.01$, unpaired $t$ test).

the medium, the medium volume and the polystyrene area in contact with the exposure solution. A low partitioning to plastics has also been predicted for two other chemicals with similar $\log K_{\text {ow }}$, namely malathion with a $\log K_{\text {ow }}$ of 2.36 and cyproconazole with a $\log K_{\text {ow }}$ of 2.9 , as analyzed by StadnickaMichalak et al. ${ }^{33}$ Third, as the Henry's Law constant of CDNB $\left(K_{\mathrm{H}}=2 \times 10^{-06}\left[\mathrm{~m}^{3} \mathrm{~atm} / \mathrm{mol}\right]^{30}\right)$ is in the same order of magnitude as that of ethanol $\left(K_{\mathrm{H}}=5 \times 10^{-06}\left[\mathrm{~m}^{3} \mathrm{~atm} /\right.\right.$ $\left.\mathrm{mol}]^{34}\right)$, it is likely that evaporation from the medium surface provided a major contribution to CDNB loss over time.

CDNB Acute Toxicity in PAC2 Cells Is Similar to Acute Toxicity in Aquatic Organisms. Assessment of PAC2 cell viability upon CDNB exposure essentially followed the protocol developed for rainbow trout (Oncorhynchus mykiss) gill cells, RTgill-W1, for predicting acute fish toxicity. The standardized RTgill-W1-based protocol recommends calculating the $\mathrm{EC}_{50}$ values based on the geometric mean of concentrations measured at the beginning $\left(\mathrm{C}_{0 h}\right)$ and at the end $\left(\mathrm{C}_{24 \mathrm{~h}}\right)$ of the exposure (ISO 21115; Tanneberger et al. 2013). In the case of PAC2 cells and CDNB, this amounted to an overall $\mathrm{EC}_{50(\overline{\mathrm{x}} \text { geomean })}$ of $220 \mathrm{ng} / \mathrm{mL}(1.1 \mu \mathrm{M})$. This value is two times higher than the recently reported $\mathrm{LC}_{50}$ of zebrafish early life stages (Danio rerio, $96 \mathrm{~h}$ zFET, $\mathrm{LC}_{50}=107 \mathrm{ng} / \mathrm{mL}$ $\left.(0.53 \mu \mathrm{m}),{ }^{21}\right)$ and is within the range of median lethal concentrations $\left(\mathrm{LC}_{50}\right)$ previously published for other aquatic organisms, such as fish (Poecilia reticulata, $\mathrm{LC}_{50(14 \mathrm{~d})}=200 \mathrm{ng} /$ $\mathrm{mL}, 1.0 \mu \mathrm{M}$ ), water flea (Daphnia magna, $\mathrm{LC}_{50(48 \mathrm{~h})}=800 \mathrm{ng} /$ $\mathrm{mL}, 3.9 \mu \mathrm{M}$ and $\left.\mathrm{LC}_{50(21 \mathrm{~d})}=430 \mathrm{ng} / \mathrm{mL}, 2.1 \mu \mathrm{M}\right)$ and rotifer (Brachionus calyciflorus $\left.\mathrm{LC}_{50(24 \mathrm{~h})}=1300 \mathrm{ng} / \mathrm{mL}, 6.4 \mu \mathrm{M}\right){ }^{30}$ The $\mathrm{NtC}_{(\bar{x} \text { geomean) }}$ was calculated to be $86 \mathrm{ng} / \mathrm{mL}(0.4 \mu \mathrm{M})$, which is roughly 4 times higher than the $\mathrm{NtC}$ of zebrafish early life stages (Danio rerio, $96 \mathrm{~h} \mathrm{zFET}, \mathrm{NtC}=25 \mathrm{ng} / \mathrm{mL}, 0.1$ $\mu \mathrm{M}^{21}$ One apparent difference between the cell-based assay and the zFET is the exposure medium composition. It is possible that CDNB sorbs onto proteins and lipids present in the serum supplement of the cell exposure medium used here to accommodate downstream biotransformation studies. Sorption to these serum components may result in a reduced free substance concentration and thus lead to reduced toxicity.

Representatives of All but One Cytosolic GST Class Are Detectable in the PAC2 Cell Line. PAC2 cells were found to express a wide range of cytosolic GSTs, the enzymes 

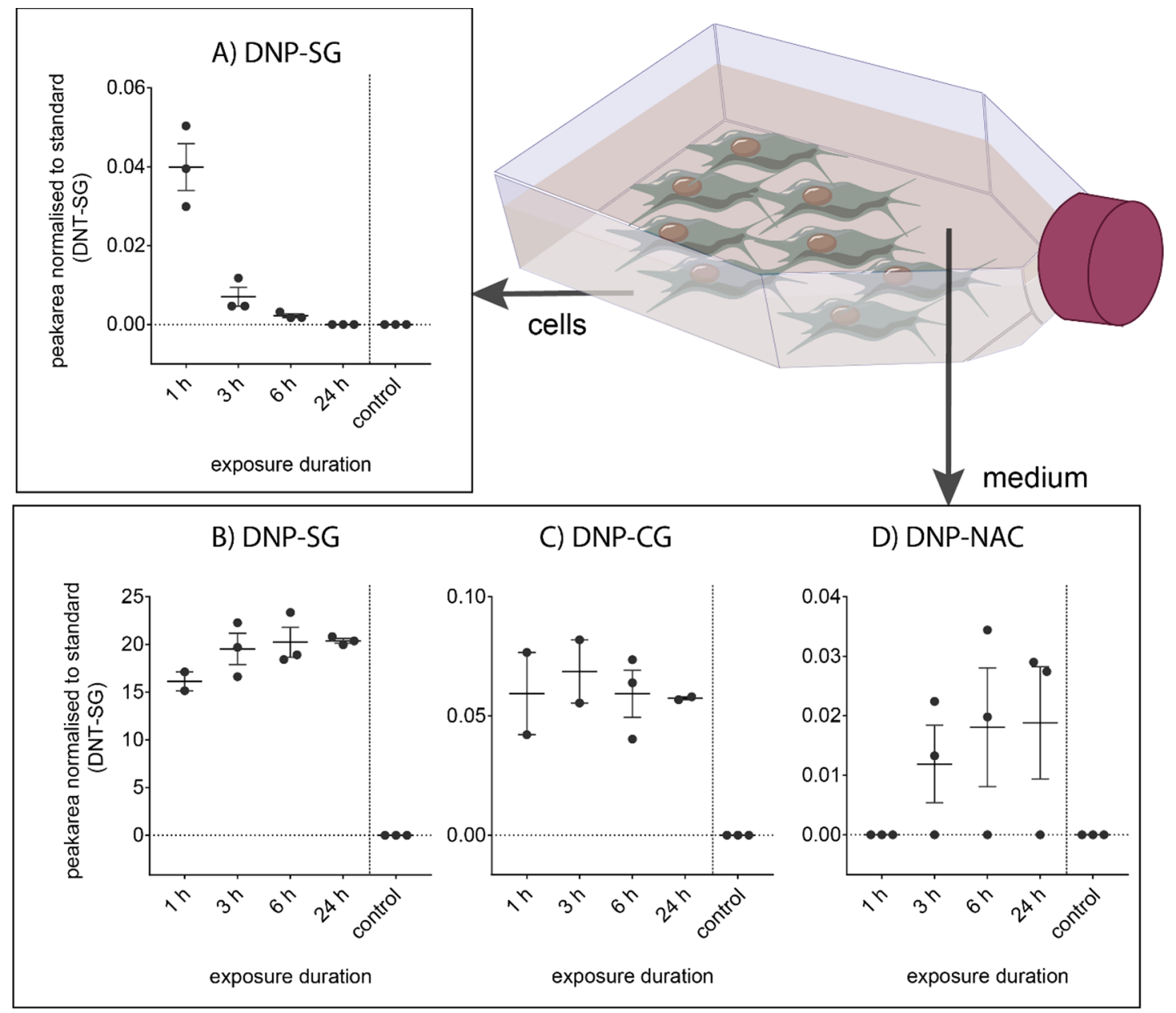

Figure 4. Biotransformation products of 1-chloro-2,4-dinitrobenzene (CDNB) detected in PAC2 cell lines (A) and medium (B-D) upon cell exposure to the nontoxic concentration of CDNB. Exposed cells (one confluent T75 culture flask/replicate) and medium were sampled after 1, 3, 6 , and $24 \mathrm{~h}$ of exposure. Control cells (not exposed) were sampled at the $24 \mathrm{~h}$ time point. Panels A and B show 2,4-dinitrophenyl-S-glutathione (DNP-SG) measured in cells and medium, respectively. Panel C shows 2,4-dinitrophenyl cysteinylglycine (DNP-CG) measured in medium and panel D shows 2,4-dinitrophenyl $N$-acetylcysteine (DNP-NAC) measured in medium. 2,4-Dinitrophenyl cysteinylglycine (DNP-C) was not detected in any of the samples. Data represents the peak area normalized to the standard 2,4-dinitrotoluene-S-glutathione (DNT-SG). Each data point represents an independent replicate, shown in addition to the mean and standard error.

that catalyze the initial reaction of the mercapturic acid pathway. The protein expression of this important family of enzymes has previously been characterized in zebrafish early life stages (age 4 to $168 \mathrm{hpf}$ ) and organs of adult zebrafish. ${ }^{27}$ It was shown that only enzymes belonging to the cytosolic GST classes alpha, mu, pi, rho, and omega are expressed in zebrafish embryos (age 4 to $48 \mathrm{hpf}$ ), while in free swimming larvae (75 to $168 \mathrm{hpf}$ ) as well as in adult fish, all cytosolic GST classes are present. ${ }^{27}$ The PAC2 cell line has been derived from $24 \mathrm{hpf}$ old zebrafish embryos. ${ }^{20}$ Compared with the donor organism, a large overlap but also some differences in the expression patterns of GSTs can be observed. Namely, in addition to mu, pi, rho, and omega, the GST classes zeta and theta, not expressed in the $24 \mathrm{hpf}$ embryos, could be identified in the PAC2 cells. In contrast, the GST class alpha, prominently expressed in the embryos, was not detectable in the embryonic cell line. One explanation for this surprising observation could be that in this cell line, the GST alpha enzymes are regulated by unknown posttranslational modifications, and these modified peptides cannot be detected by our targeted proteomics method. However, similar to our findings, microarray data of $\mathrm{He}$ and co-workers (2006) revealed the
mRNA expression of GST classes mu, pi, rho, omega, and theta in PAC2 cells, but reported no information for the GST classes alpha and zeta. ${ }^{15}$ Taken together, the findings on both the mRNA and protein expression levels thus suggest that the GST class alpha could indeed be absent in PAC2 cells. It is not unexpected for cultured cells to have a protein expression pattern or posttranslational regulation distinct from the donor organism, as this could be caused by adaptations to cell culture conditions. $^{35}$

It has been hypothesized that the GST class alpha plays an important role in detoxification of therapeutic drugs, carcinogens, and environmental pollutants. ${ }^{36}$ This assumption is supported by the fact that GSTA1 is the most abundant cytosolic GST isoenzyme in adult human liver. ${ }^{37-39}$ The class alpha showed strong hepatic expression in adult zebrafish as well. ${ }^{27}$ Nevertheless, since GSTs have overlapping substrate specificities, ${ }^{40,41}$ the revealed potential lack of GST class alpha is not likely to have substantial consequences for the biotransformation capacity of PAC2 cells.

Cytosolic GST Protein Expression Is Not Affected by Low Concentrations of a Model Substrate. Upon a single exposure to a nontoxic concentration of the model electro- 
phile, CDNB, the protein expression of cytosolic GSTs was not affected. These results are in agreement with a study performed in zebrafish early life stages where exposure to a low CDNB concentration also did not alter cytosolic GST expression. ${ }^{21}$ GST genes are known to be regulated by several responsive elements involved in xenobiotic defense, including antioxidant or electrophile responsive element (ARE/EpRE), ${ }^{42,43}$ aryl hydrocarbon receptor (AhR), ${ }^{42,44}$ and nuclear factor-like 2 (Nrf2) transcription factor. ${ }^{42,45,46}$ However, since the CDNB exposure concentration was low, it is plausible to assume that the cellular damage remained below the level necessary to activate a cellular defense mechanism on the gene expression level.

Mercapturic Acid Pathway Is Functional in PAC2 Cells. Supported by the identification of all but one CDNB biotransformation product, the mercapturic acid pathway appears fully active in the PAC2 cell line. In agreement with these observations, our analysis of raw microarray data provided by He et al. ${ }^{15}$ in the ArrayExpress database (www. ebi.ac.uk/arrayexpress/) revealed that PAC2 cells express not only multiple GSTs but also at least one $\gamma$-glutamyl transferase and several dipeptidases and $N$-acetyltransferases, i.e., enzymes catalyzing other reactions in the mercapturic acid pathway.

Our data show that PAC2 cells produce the DNP-SG conjugate internally (Figure 4A), but no other biotransformation products could be detected in the cells. We hypothesize that, upon internal production, DNP-SG is transported to the cell surface. It is possible that, since there are no other protective layers, some of the DNP-SG conjugates then diffuse from the cell surface and into the medium (volume $\sim 10 \mathrm{~cm}^{3}$; Figure $4 \mathrm{~B}$ ), and only the DNP-SG conjugates remaining in close proximity to the cell membrane are further biotransformed to DNP-CG. This would explain the generally lower concentrations of detected biotransformation products other than DNP-SG. Similarly, some of the produced DNP-CG conjugates are further diluted (Figure 4C) before being biotransformed to the short-living intermediate DNP-C. Although we did not detect DNP-C in our system, the presence of the subsequent biotransformation product of the pathway (DNP-NAC) indicates that this intermediate biotransformation step has also occurred. DNP-C is apparently taken up by the cells and acetylated to DNP-NAC, which is then excreted into the medium as the final excretion product of the mercapturic acid pathway (Figure 4D).

In a previous study performed with zebrafish embryos and larvae, ${ }^{21}$ no biotransformation products of the mercapturic acid pathway could be detected in the medium, but the fish tissue contained both the first (DNP-SG) and the last (DNP-NAC) biotransformation product of the mercapturic acid pathway. This difference to the cell culture findings could be explained by the fact that in a complex organism, such as zebrafish embryo, the tissue space is typically confined, while in our system the PAC2 cells are grown as a single cell layer with a large volume of surrounding cell culture medium. In the tissue, where the intracellular space is limited, the intermediate biotransformation products (DNP-CG and DNP-C) are likely to remain in close proximity to the cell surface were they are quickly and efficiently further biotransformed by membranebound extracellular enzymes ${ }^{21}$ (Figure 1). Since no transfer into the surrounding medium occurs, as appears to be the case in the cell culture system, the intermediate products subject to ongoing biotransformation reactions do not reach a concentration detectable by available LC-MS techniques. Further, the final excretion is also likely to be slower in the embryo, leading to accumulation and hence detection of the final excretion product, DNP-NAC, in the organism.

We found that the GST expression of the PAC2 cell line somewhat differs from the expression pattern of zebrafish early life stages and adult fish. However, we also show that the cell line nonetheless retains the capacity to biotransform the model compound $\mathrm{CDNB}$ to the respective glutathione conjugate. Indeed, the PAC2 cells express all enzymes involved in the mercapturic acid pathway and thus, similar to the donor organism zebrafish embryo, have the potential to perform all reactions of the mercapturic acid pathway.

In conclusion, the ability of the PAC2 cell line to fully express the mercapturic acid pathway provides impetus to use this cell line for screening compound libraries with a focus on electrophiles for detoxification and bioactivation. Certain adaptation could provide means to further expand on this potential of the cells. For example, use of 3D cultures may allow for a closer mimic of a confined tissue space where biotransformation can proceed with less loss of the substrate in the exposure medium.

\section{ASSOCIATED CONTENT}

\section{sI Supporting Information}

The Supporting Information is available free of charge at https://pubs.acs.org/doi/10.1021/acs.chemrestox.0c00315.

Nominal and measured 1-chloro-2,4-dinitrobenzene (CDNB) concentrations; mean of EC50 and nontoxic concentration $(\mathrm{NtC})$ values; dose-response data for cell viability; expression of cytosolic GSTs in PAC2 cells cultured in L-15 medium; mass spectra of 2,4dinitrotoluene-S-glutathione, 2,4-dinitrophenyl-S-glutathione, 2,4-dinitrophenyl cysteinglycine, and 2,4-dinitrophenyl $\mathrm{N}$-acetylcysteine; and difference (ppm) between the measured and predicted isotopes; kinetic model of the 1-chloro-2,4-dinitrobenzene (CDNB) concentration in T75 cell culture flasks; generation of DNP-CG through gas-phase reactions in the ESI source (PDF)

\section{AUTHOR INFORMATION}

\section{Corresponding Authors}

Kristin Schirmer - Eawag, Swiss Federal Institute of Aquatic Science and Technology, 8600 Dübendorf, Switzerland; School of Architecture, Civil and Environmental Engineering, EPFL Lausanne, 1015 Lausanne, Switzerland; Swiss Federal Institute of Technology, Department of Environmental Systems Science, ETH Zürich, 8092 Zürich, Switzerland; ○ orcid.org/00000003-1116-4724; Email: kristin.schirmer@eawag.ch

Marc J.-F. Suter - Eawag, Swiss Federal Institute of Aquatic Science and Technology, 8600 Dübendorf, Switzerland; Swiss Federal Institute of Technology, Department of Environmental Systems Science, ETH Zürich, 8092 Zürich, Switzerland; () orcid.org/0000-0003-3762-3490; Phone: +41 58765 5479; Email: marc.suter@eawag.ch

\section{Authors}

Alena Tierbach - Eawag, Swiss Federal Institute of Aquatic Science and Technology, 8600 Dübendorf, Switzerland; School of Architecture, Civil and Environmental Engineering, EPFL Lausanne, 1015 Lausanne, Switzerland 
Ksenia J. Groh - Food Packaging Forum Foundation, 8045 Zürich, Switzerland

René Schoenenberger - Eawag, Swiss Federal Institute of Aquatic Science and Technology, 8600 Dübendorf, Switzerland

Complete contact information is available at: https://pubs.acs.org/10.1021/acs.chemrestox.0c00315

\section{Funding}

This work was supported by the Swiss Federal Institute of Aquatic Science and Technology (Eawag).

\section{Notes}

The authors declare no competing financial interest.

\section{ACKNOWLEDGMENTS}

We thank Melanie Fischer and Nadine Bramaz for the assistance with cell culturing.

\section{REFERENCES}

(1) Armstrong, R. N., Morgenstern, R., and Board, P. G. (2018) Glutathione Transferases. Comprehensive Toxicology, 328-362.

(2) Cooper, A. J. L., and Hanigan, M. H. (2018) Metabolism of Glutathione S-Conjugates - Multiple Pathways. Comprehensive Toxicology, 363-406.

(3) Hanna, P. E., and Anders, M. W. (2019) The mercapturic acid pathway. Crit. Rev. Toxicol. 49, 819-929.

(4) Habig, W. H., Pabst, M. J., and Jakoby, W. B. (1974) Glutathione S-transferases. The first enzymatic step in mercapturic acid formation. J. Biol. Chem. 249, 7130-7139.

(5) Armstrong, R. N. (1997) Structure, catalytic mechanism, and evolution of the glutathione transferases. Chem. Res. Toxicol. 10, 2-18.

(6) Ursic, D., Berginc, K., Zakelj, S., and Kristl, A. (2009) Influence of luminal monosaccharides on secretion of glutathione conjugates from rat small intestine in vitro. Int. J. Pharm. 381, 199-204.

(7) Ballatori, N., Krance, S. M., Marchan, R., and Hammond, C. L. (2009) Plasma membrane glutathione transporters and their roles in cell physiology and pathophysiology. Mol. Aspects Med. 30, 13-28.

(8) Pompella, A., De Tata, V., Paolicchi, A., and Zunino, F. (2006) Expression of gamma-glutamyltransferase in cancer cells and its significance in drug resistance. Biochem. Pharmacol. 71, 231-238.

(9) Dilda, P. J., Ramsay, E. E., Corti, A., Pompella, A., and Hogg, P. J. (2008) Metabolism of the Tumor Angiogenesis Inhibitor 4-(N-(SGlutathionylacetyl)amino) phenylarsonous Acid. J. Biol. Chem. 283, 35428-35434.

(10) Hinchman, C. A., Rebbeor, J. F., and Ballatori, N. (1998) Efficient hepatic uptake and concentrative biliary excretion of a mercapturic acid. Am. J. Physiol.-Gastrointest. Liver Physiol. 275, G612-G619.

(11) Garnier, N., Redstone, G. G. J., Dahabieh, M. S., Nichol, J. N., del Rincon, S. V., Gu, Y. X., Bohle, D. S., Sun, Y., Conklin, D. S. Mann, K. K., and Miller, W. H. (2014) The Novel Arsenical Darinaparsin Is Transported by Cystine Importing Systems. Mol. Pharmacol. 85, 576-585.

(12) Monks, T. J., Anders, M. W., Dekant, W., Stevens, J. L., Lau, S. S., and Bladeren, P. J. v. (1990) Contemporary issues in toxicology. Glutathione conjugate mediated toxicities. Toxicol. Appl. Pharmacol. $106,1-19$.

(13) Vamvakas, S., and Anders, M. W. (1991) Formation of reactive intermediates by phase II enzymes: glutathione-dependent bioactivation reactions. Adv. Exp. Med. Biol. 283, 13-24.

(14) Bakke, J., and Gustafsson, J. A. (1984) Mercapturic Acid Pathway Metabolites of Xenobiotics - Generation of Potentially Toxic Metabolites during Enterohepatic Circulation. Trends Pharmacol. Sci. $5,517-521$.

(15) He, S., Salas-Vidal, E., Rueb, S., Krens, S. F., Meijer, A. H., Snaar-Jagalska, B. E., and Spaink, H. P. (2006) Genetic and transcriptome characterization of model zebrafish cell lines. Zebrafish 3, 441-453.

(16) Klobucar, R. S., Brozovic, A., and Stambuk, A. (2013) Ecotoxicological Assessment of Nitrofurantoin in Fish Cell Lines, Unicellular Algae Desmodesmus subspicatus, and Bacterial Strains of Salmonella typhimurium. Fresenius Environ. Bull. 22, 2669-2675.

(17) Srut, M., Bourdineaud, J. P., Stambuk, A., and Klobucar, G. I. (2015) Genomic and gene expression responses to genotoxic stress in PAC2 zebrafish embryonic cell line. J. Appl. Toxicol. 35, 1381-1389.

(18) Boxtel, A. L. v., Kamstra, J. H., Cenijn, P. H., Pieterse, B., Wagner, M. J., Antink, M., Krab, K., Burg, B. v. d., Marsh, G., Brouwer, A., and Legler, J. (2008) Microarray analysis reveals a mechanism of phenolic polybrominated diphenylether toxicity in zebrafish. Environ. Sci. Technol. 42, 1773-1779.

(19) van Boxtel, A. L., Pieterse, B., Cenijn, P., Kamstra, J. H., Brouwer, A., van Wieringen, W., de Boer, J., and Legler, J. (2010) Dithiocarbamates induce craniofacial abnormalities and downregulate sox9a during zebrafish development. Toxicol. Sci. 117, 209-217.

(20) Lin, S., Gaiano, N., Culp, P., Burns, J. C., Friedmann, T., Yee, J. K., and Hopkins, N. (1994) Integration and germ-line transmission of a pseudotyped retroviral vector in zebrafish. Science 265, 666-669.

(21) Tierbach, A., Groh, K. J., Schoenenberger, R., Schirmer, K., and Suter, M. J. (2020) Biotransformation capacity of zebrafish (Danio rerio) early life stages: Functionality of the mercapturic acid pathway. Toxicol. Sci. 176, 355-365.

(22) Tanneberger, K., Knobel, M., Busser, F. J., Sinnige, T. L., Hermens, J. L., and Schirmer, K. (2013) Predicting fish acute toxicity using a fish gill cell line-based toxicity assay. Environ. Sci. Technol. 47, 1110-1119.

(23) Fischer, M., Belanger, S. E., Berckmans, P., Bernhard, M. J., Bláha, L., Coman Schmid, D. E., Dyer, S. D., Haupt, T., Hermens, J. L. M., Hultman, M. T., Laue, H., Lillicrap, A., Mlnaríková, M., Natsch, A., Novák, J., Sinnige, T. L., Tollefsen, K. E., von Niederhäusern, V., Witters, H., Županič, A., and Schirmer, K. (2019) Repeatability and Reproducibility of the RTgill-W1 Cell Line Assay for Predicting Fish Acute Toxicity. Toxicol. Sci. 169, 353-364.

(24) ISO. (21115:2019) Water quality-Determination of acute toxicity of water samples and chemicals to a fish gill cell line (RTgill$\mathrm{W} 1)$.

(25) Schirmer, K., Chan, A. G., Greenberg, B. M., Dixon, D. G., and Bols, N. C. (1998) Ability of 16 priority PAHs to be photocytotoxic to a cell line from the rainbow trout gill. Toxicology 127, 143-155.

(26) Tierbach, A., Groh, K. J., Schonenberger, R., Schirmer, K., and Suter, M. J. (2020) LC-APCI(-)-MS Determination of 1-Chloro-2,4dinitrobenzene, a Model Substrate for Glutathione S-Transferases. J. Am. Soc. Mass Spectrom. 31, 467.

(27) Tierbach, A., Groh, K. J., Schonenberger, R., Schirmer, K., and Suter, M. J. F. (2018) Glutathione S-Transferase Protein Expression in Different Life Stages of Zebrafish (Danio rerio). Toxicol. Sci. 162, $702-712$.

(28) Stadnicka-Michalak, J., Knobel, M., Zupanic, A., and Schirmer, K. (2018) A validated algorithm for selecting non-toxic chemical concentrations. ALTEX 35, 37-50.

(29) MacLean, B., Tomazela, D. M., Shulman, N., Chambers, M., Finney, G. L., Frewen, B., Kern, R., Tabb, D. L., Liebler, D. C., and MacCoss, M. J. (2010) Skyline: an open source document editor for creating and analyzing targeted proteomics experiments. Bioinformatics 26, 966-968.

(30) HSDB. (2019) Hazardous Substances Data Bank [Internet]. National Library of Medicine (US), Bethesda, MD; [5/17/2012; cited 2019]. 1-CHLORO-2,4-DINITROBENZENE; Hazardous Substances Databank Number: 5306. Available from: http://toxnet. nlm.nih.gov/cgi-bin/sis/htmlgen?HSDB.

(31) Fischer, F. C., Cirpka, O. A., Goss, K. U., Henneberger, L., and Escher, B. I. (2018) Application of Experimental Polystyrene Partition Constants and Diffusion Coefficients to Predict the Sorption of Neutral Organic Chemicals to Multiwell Plates in in Vivo and in Vitro Bioassays. Environ. Sci. Technol. 52, 13511-13522. 
(32) Debnath, A. K., Lopez de Compadre, R. L., Debnath, G., Shusterman, A. J., and Hansch, C. (1991) Structure Activity Relationship of Mutagenic Aromatic and Heteroaromatic NitroCompounds - Correlation with Molecular-Orbital Energies and Hydrophobicity. J. Med. Chem. 34, 786-797.

(33) Stadnicka-Michalak, J., Tanneberger, K., Schirmer, K., and Ashauer, R. (2014) Measured and modeled toxicokinetics in cultured fish cells and application to in vitro-in vivo toxicity extrapolation. PLoS One 9, e92303.

(34) Sander, S. P., Abbatt, J., Barker, J. R., Burkholder, J. B., Friedl, R. R., Golden, D. M., Huie, R. E., Kolb, C. E., Kurylo, M. J., Moortgat, G. K., Orkin, V. L., and Wine, P. H. (2011) Chemical Kinetics and Photochemical Data for Use in Atmospheric Studies, Evaluation No. 17, JPL Publication 10-6; Jet Propulsion Laboratory, Pasadena, http:// jpldataeval.jpl.nasa.gov.

(35) Fischer, S., Loncar, J., Zaja, R., Schnell, S., Schirmer, K., Smital, T., and Luckenbach, T. (2011) Constitutive mRNA expression and protein activity levels of nine $A B C$ efflux transporters in seven permanent cell lines derived from different tissues of rainbow trout (Oncorhynchus mykiss). Aquat. Toxicol. 101, 438-446.

(36) Hollman, A. L., Tchounwou, P. B., and Huang, H. C. (2016) The Association between Gene-Environment Interactions and Diseases Involving the Human GST Superfamily with SNP Variants. Int. J. Environ. Res. Public Health 13, 379.

(37) Mainwaring, G. W., Williams, S. M., Foster, J. R., Tugwood, J., and Green, T. (1996) The distribution of theta-class glutathione Stransferases in the liver and lung of mouse, rat and human. Biochem. J. 318, 297-303.

(38) Rowe, J. D., Nieves, E., and Listowsky, I. (1997) Subunit diversity and tissue distribution of human glutathione S-transferases: Interpretations based on electrospray ionization MS and peptide sequence-specific antisera. Biochem. J. 325, 481-486.

(39) Coles, B. F., and Kadlubar, F. F. (2003) Detoxification of electrophilic compounds by glutathione S-transferase catalysis: Determinants of individual response to chemical carcinogens and chemotherapeutic drugs? (Reprinted from Thiol Metabolism and Redox Regulation of Cellular Functions). BioFactors 17, 115-130.

(40) Mannervik, B., Helena Danielson, U., and Ketterer, B. (1988) Glutathione transferases-structure and catalytic activity. CRC Crit Rev. Biochem 23, 283-337.

(41) Glisic, B., Mihaljevic, I., Popovic, M., Zaja, R., Loncar, J., Fent, K., Kovacevic, R., and Smital, T. (2015) Characterization of glutathione-S-transferases in zebrafish (Danio rerio). Aquat. Toxicol. $158,50-62$.

(42) Knight, T. R., Choudhuri, S., and Klaassen, C. D. (2008) Induction of hepatic glutathione $\mathrm{S}$-transferases in male mice by prototypes of various classes of microsomal enzyme inducers. Toxicol. Sci. 106, 329-338.

(43) van Bladeren, P. J. (2000) Glutathione conjugation as a bioactivation reaction. Chem.-Biol. Interact. 129, 61-76.

(44) Higgins, L. G., and Hayes, J. D. (2011) Mechanisms of induction of cytosolic and microsomal glutathione transferase (GST) genes by xenobiotics and pro-inflammatory agents. Drug Metab. Rev. 43, 92-137.

(45) Ma, Q. (2013) Role of nrf2 in oxidative stress and toxicity. Annu. Rev. Pharmacol. Toxicol. 53, 401-426.

(46) Chanas, S. A., Jiang, Q., McMahon, M., McWalter, G. K., McLellan, L. I., Elcombe, C. R., Henderson, C. J., Wolf, C. R., Moffat, G. J., Itoh, K., Yamamoto, M., and Hayes, J. D. (2002) Loss of the $\mathrm{Nrf} 2$ transcription factor causes a marked reduction in constitutive and inducible expression of the glutathione S-transferase Gstal, Gsta2, Gstm1, Gstm2, Gstm3 and Gstm4 genes in the livers of male and female mice. Biochem. J. 365, 405-416. 